\title{
Knowledge, Attitude and Acceptance of Modern Family Planning Method Among Women Attending Post-Natal Clinic in Ayeka Basic Health Centre in Okitipupa Local Government Area, Ondo State, Nigeria
}

\author{
Obalase Stephen Babatunde ${ }^{1 *}$ and Joseph Uchenna Evelyn ${ }^{2}$ \\ ${ }^{1}$ Federal University of Technology, Nigeria \\ ${ }^{2}$ Ondo State Primary Health Management Board Agency, Nigeria
}

Received: September 04, 2017; Published: September 15, 2017

*Corresponding author: Obalase Stephen Babatunde, Federal university of technology, health centre, Akure, Nigeria, Email: obalase@yahoo.com

\begin{abstract}
Unintended or unplanned pregnancy poses a major economical, psychological, social, and/or religious challenge in women of reproductive age, especially in developing countries. Available data indicates that Nigeria currently has one of the highest rates of maternal mortality in the world. It is also in evidence that $40 \%$ of these maternal deaths are due to complications of unsafe abortions which often is a response to an unwanted pregnancy that could have been prevented by effective contraceptive programming. Yet Nigeria's contraceptive prevalence rate is less than $13 \%$. This was a descriptive cross sectional survey carried out amongst Women Attending Post-Natal Clinic in Ayeka Basic Health Centre in Okitipupa Local Government Area of Ondo State a simple questionnaire exploring Knowledge, Attitude and Acceptance of Modern Family Planning Method. Information obtained included bio data, knowledge and awareness information, practice. Data were analyzed using frequency and percentage counts statistics. A total of 200 women with 107 below 31, 78 were between age 31-40 and 15 were greater than 40 ). Majority 157 (78.5\%) have heard about contraceptive while 55(27.5\%) heard the information from government hospital/health care. Majority could identify contraceptive method. The major barrier to the usage of contraceptive was husband's refusal. This study concluded that there is high level of awareness of contraceptive among women attending Post Natal Clinic in Ayeka Basic Health Centre in Okitipupa Local Government area. There is a low level of Spousal communications among the respondents as only $43.5 \%$ of respondents discuss contraceptive with spouses and partners.
\end{abstract}

Keywords: Knowledge; Attitude; Acceptance; Modern family planning

Abbreviation: UNICEF: United Nations International Children Emergency Fund; PPFA: Planned Parenthood Federation Association; STI: Sexually Transmitted Infections; NPC: Nigeria Population Commission; CPR: Contraceptive Prevalence Rate; MFPM: Modern Family Planning Methods; IUD: Intra Uterine Device; NHIS: National Health Insurance Scheme; NGOs: Non-Governmental Organizations

\section{Introduction}

As a result of the current population of Nigeria, this is 187, 754, and 280 as of Friday September 2, 2016 based on the latest United Nations estimates. Its population is equivalent to $2.48 \%$ of the total world population. Nigeria ranks number 7 in the list of country by population. The population density in Nigeria is 205 per $\mathrm{km}^{2}$ (532 people per $\mathrm{m}^{2}$ ). In order to curb the population increase, efforts have been made by both the federal government of Nigeria and World International Organization (WHO), United Nations International Children Emergency Fund (UNICEF), planned Parenthood Federation Association (PPFA) to increase awareness, attitude and practice of family planning among all reproductive age groups including adolescents. This increase in attitude, knowledge and practice among the women of child bearing age (15-45) is yet to be effective among the women in the rural areas of most developing countries where majority of the population live (Adeleye et al. 2010).

It is now a fundamental human right throughout the World for individuals to manage their fertility. Information and medical services related to sexuality, reproduction, contraception and fertility control should be made available to all regardless of their individual income, marital status, race, ethnicity, sexual orientation, age nationality or residence Planned Parenthood federation [1]. Sexually transmitted infections (STI) are stern health challenge with a worldwide prevalence of 333 million new cases each year 
[2]. Young adults are at risks of contracting STIs mainly through sexual intercourse as a result off their physical, psychosomatic, social and economic characteristics of young adults [3] and they are also vulnerable due to high levels of risky sexual behaviours and the attitudes, expectations and restriction of the cultures in which they grow up. Such reproductive health behavior is prone to consequences, unsafe of unwanted pregnancies, unsafe abortions, disruption of education, sexually transmitted diseases, and secondary infertility [4].

It has been reported by the Nigeria Population Commission (NPC) that the knowledge of family planning with no education is the lowest among women and greatest with more than Secondary education [5]. Modern family planning use has risen in the developed world compared to the developing countries in which Nigeria in inclusive. Nigeria is already facing a population explosion with the resultant effect that food reproduction cannot, match the growing population [2]. In Nigeria today, the birth rate are higher than the World averages [6].

The current growth rate of 2.38\% Nigeria adds 3.7 million people to the worlds [5] (Microsoft Encarta, 2008). Contraceptive prevalence Rate (CPR) is still embarrassing low in Nigeria according to the report released. By the international women's health coalition, the CPR among married women aged 15-5 years was $8 \%$ for modern methods and $12 \%$ for all methods and $12 \%$ for all methods. Also, other studies have reported a similarly low adoption rate of modern family planning methods (MFPM).

According to Weldegerima, Denekew [4], one of the major factors is that the women of reproductive age often lack basic information on the consequences of sexual intercourse, knowledge about affordable confidential reproductive health services. Family planning programmes strive to prevent unwanted pregnancies, help achieve birth spacing and help couples limit family size so as to reduce maternal mortality, STIs. The present study is therefore, designed to examine the knowledge, attitude and acceptance of modern family planning methods among woman (15- 45 years) attending post- natal clinic in Ayeka community, Okitipupa Local Government Area of Ondo State, Nigeria.

\section{Justification / Significance of the Study/Need of the Study}

The justification for the study includes the incessant unhealthy attitude of child abandonment, child abuse and child neglect among couples with many children. Most of the couples in this low rural setting were majorly low income earners, illiterate and polygamous in marriage system by way of their culture. The desire to have a male child most often prompted them to have many children that they cannot carter for. Finally, are facilities and personnel's for modern family planning readily available? The study could benefit health care providers, couples, policy makers at all tiers of government, nongovernmental organization and the entire community. The federal, state and local government could also benefit from the findings in providing comprehensive care and support programmes to women confronted by the challenges of child neglect, child abandonment, too many unwanted children and child labour. It will also provide baseline data that could be used to plan further interventions to enhance acceptance of modern family planning methods.

\section{Statement of the Problem}

Women of reproductive age (15-45 years) maybe married or not married. Most of them know little or incorrect information about modern family planning methods. Even when they know some names of contraceptives, they don't know where to get them or how to use it. These women have negative attitude about family planning, while some have heard false and misleading information. The poor correspondence between knowledge, attitude and acceptance of modern family planning methods has drawn attention to women's perception about the positive and negative aspect of Modern contraception [7,8] noted that the reluctance to use modern methods stemmed from fear that uses might cause infertility, producing damaging side effects and forgetting to take the contraceptive pills was a serious risk.

Another perceived barrier to the modern method is that, they believed that only commercial sex workers should be involved in the art of F/P they believed that women don't need it since she is living with the husband and for that should have as many children as possible so far God gives, he will provide for them. While, some couples believe that the use of condoms are unnatural and unhygienic thereby reduce the pleasure or sensation [2] and that their use is complete lack of respect to their partner. Others believe that if their wives use any of the modern methods, she has engaged in extra-marital affairs. Nevertheless, some believe that like the IUD (Intra Uterine Device) use to dry their blood. Some said they have heavy menstrual flow [8]. While those that uses implant said that it causes numbness to their body.

However, the age at which the woman engages in sexual activities varies considerably depending on the various socializing influences and the opportunities available for practicing sexual behaviors [9]. For instance, the economic situation of the individuals, Lifestyle or family history that is some families are believe not to stay in an husbands house or don't want to give birth to only one man; or a polygamous family where there are competition to give birth as many times as possible. Based on these, this study aims at examining the knowledge attitude and acceptance of modern family planning methods among women ages 15-45 years in Ayeka Community, Okitipupa local Government of Ondo State.

\section{Objectives of the Study}

a. To examine the level of women use of modern family planning methods in Ayeka Community

b. To identify factors that is responsible for the level of women's knowledge, attitudes and acceptance of modern family planning methods.

c. To find out the effectiveness of modern family planning methods for the respondents. 
d. To find out the women's level of knowledge about modern family planning methods available in the facilities.

e. To know the women's knowledge about the means of accessibility to modern family planning methods.

\section{Research Questions}

The following research questions are formulated to guide this study,

a. What is the level of women's is knowledge about modern family planning methods use and practice in Ayeka Community.

b. What factors are responsible for level of women's modern family planning use and practice in Ayeka.

c. How effective is modern $\mathrm{F} / \mathrm{P}$ to the respondents.

d. What are sources of information of modern F/P to the respondents?

e. What are the means of accessibility to the respondent for the service?

\section{Significance of Study}

The study will be used to determine the extent at which health education which includes family planning is effective at the grassroots. It is hoped that this study will have both theoretical and practical significance, since it is geared towards addressing an issue that is fundamental to the society at large, Nigeria in particular. Practically, the findings from the study will be used by future researchers to explore other ways of reducing maternal mortality/ morbidity, unwanted pregnancy/complications and sexually transmitted infections.

The knowledge acquired from the study will be used to create the study awareness on the modern family planning methods. To individual, families and communities, a study of this nature will help the policy on the importance of child spacing to the public as it will help in the economic development of the nation. It will equally help in the management of populations control and human resources development.

\section{Methodology}

The method used in carrying out this research work is descriptive survey design. It is used to investigate the knowledge, attitude and acceptance of modern family planning. It contains population of the study, study area, historical background studying population sample and sampling technical instrument for data collection and procedure for the data collection. The study was

Table 1: Socio-Demographical Data of Respondents. carried out in Ayeka Basic Health centre, Okitipupa L.G.A of Ondo state. The centre is a National Health Insurance Scheme (NHIS) centre where maternal and child health care services are rendered free.

The population of the study are women (15-45 years) attending post-natal care in Ayeka community in Okitipupa local Government of Ondo state. However, it is a catchment area for nursing mother, especially mother who are inhabitant of the local Government. Other tribes also live in this area where they run their day-to-day business example, Ijaws, Igbos, Hausa etc. The Ayeka Community is one of the largest communities among the communities in Okitipupa L.G.A sited at the centre of the LGA.

The study population consists of women between the ages of 15-45 years attending post natal clinic in Ayeka community using probability sampling technique to select the sample for the study. The women in this target population includes traders, farmers, civil servants, Full housewife, students, single parent are all chosen for this study. The sampling size for the study is 200 nursing mothers who purposively selected from the attendance of child welfare clinic at Ayeka Basic Health Centre/maternity. Simple random sampling will be used to select the students, traders, farmers, civil servants and housewife because of its fairness and objectivity, since everyone in the population has the chances of being selected.

There are two instruments used in this study. They are questionnaire and in-depth interview schedule. The questionnaire contains 4 sections. The first section sought the socio-demographic characteristic of the respondent in the study. The second part sought information on knowledge and use of modern family planning methods among the women ages 15-45 years in Ayeka community. The third part is to find out the attitude toward modern F/P. Fourth part is to find out the acceptance by the respondents i.e if they actually embrace the modern methods of F/P.

The data collection for this study was with the help of structured questionnaire that consist of close-ended questions and structured questions. The questionnaires were distributed to literate respondents for self administration, while the nonliterate respondents were interviewed with questionnaires as a guide in which question were translated into the language that the respondent understands. The above four section were used because they will facilitate this research more than any other techniques in gathering the desire data among the women (Table 1). The process of data analysis in this research study was descriptive and inferential statistical techniques such as frequent distribution tables and percentage measures so as to describe the attitude, knowledge and acceptance of respondents.

\begin{tabular}{|c|c|c|}
\hline Variables & Frequency & Percentage (\%) \\
\hline Sex & & 1.0 \\
\hline Male & 2 & 99.0 \\
\hline Female & 198 & \\
\hline
\end{tabular}




\begin{tabular}{|c|c|c|}
\hline $15-20$ & 30 & 15.0 \\
\hline $21-25$ & 40 & 20.0 \\
\hline $26-30$ & 37 & 18.5 \\
\hline $31-35$ & 65 & 32.5 \\
\hline $36-40$ & 13 & 6.5 \\
\hline $41-45$ & 15 & 7.5 \\
\hline \multicolumn{3}{|c|}{ Marital status } \\
\hline Single & 17 & 8.5 \\
\hline Married & 138 & 69.0 \\
\hline Divorced & 18 & 9.0 \\
\hline Separated & 13 & 6.5 \\
\hline Widow & 14 & 7.0 \\
\hline \multicolumn{3}{|c|}{ Types of marriage } \\
\hline Monogamous & 138 & 69.0 \\
\hline Polygamous & 62 & 31.0 \\
\hline \multicolumn{3}{|c|}{ Educational level } \\
\hline No education & 22 & 11.0 \\
\hline Primary & 73 & 36.5 \\
\hline Secondary & 73 & 36.5 \\
\hline Tertiary & 32 & 16.0 \\
\hline \multicolumn{3}{|c|}{ Currently working } \\
\hline Yes & 167 & 83.5 \\
\hline No & 33 & 16.5 \\
\hline \multicolumn{3}{|c|}{ Types of occupation } \\
\hline Farming & 34 & 20.4 \\
\hline Artisan & 5 & 2.9 \\
\hline Petty trading & 67 & 40.1 \\
\hline House wife & 16 & 9.6 \\
\hline Civil servant & 20 & 12.0 \\
\hline Professional & 12 & 7.2 \\
\hline Others & 13 & 7.8 \\
\hline \multicolumn{3}{|c|}{ Religion affiliation } \\
\hline Christianity & 121 & 60.5 \\
\hline Muslim & 39 & 19.5 \\
\hline Traditional & 20 & 10.0 \\
\hline Others & 20 & 10.0 \\
\hline \multicolumn{3}{|c|}{ Ethnicity } \\
\hline Yoruba & 85 & 42.5 \\
\hline Ibo & 35 & 17.5 \\
\hline Hausa & 25 & 11.0 \\
\hline Ijaw & 20 & 10.0 \\
\hline Others & 35 & 17.5 \\
\hline
\end{tabular}

\section{Results and Discussion}

The results are presented in tables and charts with brief interpretation of its content. The total number of respondents is $200(\mathrm{~N}=200)$. From the socio-demographical data distribution of the respondents, $99 \%$ are female and majority $32.5 \%$ are between the age 31 to 35 , those between the age 15 to 20 are $15 \%, 20 \%$ of the respondents are between the age $21-25$ while $18.5 \%$ are between the age 26 to 30, and the remaining $14 \%$ are between the age 36 to $45.69 \%$ of them are married, $9 \%$ are divorced $8.5 \%$ are single, $7 \%$ are widow and the remaining $6.5 \%$ are separated. Majority $69 \%$ of the women married in a monogamous setting and the rest $31 \%$ married in a polygamous setting.

It is significance to note that only $16 \%$ of the women had tertiary education, $36.5 \%$ had primary and secondary education 
and the remaining $11 \%$ had no formal education. Most $83.5 \%$ of the women are currently working while the rest $16.5 \%$ are not working. Out of the $83.5 \%$ that are working, $40.1 \%$ are petty traders, $20.4 \%$ are farmers, $12 \%$ are civil servant, $9.6 \%$ are full house wife, $7.2 \%$ are professionals, $2.9 \%$ are artisans and the remaining $7.8 \%$ didn't specify their job. Based on their religious affiliation, majority $60.5 \%$ of the women are Christians, $19.5 \%$ are Muslims, $10 \%$ are traditional and $10 \%$ didn't specify their religion. Majority $42.5 \%$ of the women are Yoruba's, $17.5 \%$ are Ibos, $11 \%$ are Hausas, $10 \%$ are Ijaws and the remaining $17.5 \%$ didn't specify their ethnic group. Ever heard about contraceptive method- Yes $=157$, No $=43$.

Table 2: Distribution of Respondent Based on their Knowledge of Contraceptive Method.

\begin{tabular}{|c|c|c|}
\hline Variables & Frequency & Percentage (\%) \\
\hline \multicolumn{3}{|c|}{ Method heard about } \\
\hline Pill & 35 & 17.5 \\
\hline Female sterilization & 5 & 2.5 \\
\hline Injection & 30 & 15 \\
\hline Jelly spermicides & 10 & 5 \\
\hline Condoms & 71 & 35.5 \\
\hline Male sterilization & 6 & 3.0 \\
\hline Implant & 17 & 8.5 \\
\hline IUCD & 26 & 13 \\
\hline \multicolumn{3}{|c|}{ Source of information } \\
\hline Television & 23 & 11.5 \\
\hline Radio & 35 & 17.5 \\
\hline Hospital & 55 & 27.5 \\
\hline Printed media & 16 & 8 \\
\hline Husband & 10 & 5.0 \\
\hline Others & 18 & 9.0 \\
\hline
\end{tabular}

Showing the distribution of the respondents based on their knowledge of contraceptive methods (Table 2), it showed that 157 (78.5\%) of the women had heard about one contraceptives methods or the other. Only $43(21.5 \%)$ of them had never heard about any contraceptive methods. On the method heard about, 23(11.5\%) heard about pills, $15 \%$ injections, $35.5 \%$ condoms, $13 \%$ IUCD, $8.5 \%$ implant, $5 \%$ jelly spermicides, $2.5 \%$ and $3.0 \%$ female and male sterilization respectively. On the source of their information, most $27.5 \%$ heard from the hospital, $17.5 \%$ from the radio, $11.5 \%$ from the television, $8 \%$ from the print media, $5 \%$ from their husband and the rest $9 \%$ didn't specify their source of information.

Based on the distribution of the women on their attitudes towards the use of contraceptives, about $50 \%$ of them agree to like women who use contraceptives, $20 \%$ strongly agree with that too, while $15 \%$ of them disagree and strongly disagree. $50 \%$ of the women are also interested in discussing with women who practice modern family planning, $22.5 \%$ strongly showed their interest in such a woman while $12.5 \%$ and $15 \%$ disagree and strongly disagree with it. Only $12.5 \%$ of the women claimed to be strongly scared of women using modern family planning, $15 \%$ also agree to be scared but $50 \%$ and $22.5 \%$ claimed not to be scared of women using modern family planning methods. Just $5 \%$ and $9.5 \%$ of the women believed that women using modern family planning methods are promiscuous, the remaining $25 \%$ and $60.5 \%$ of them disagree and strongly disagree with that. $60 \%$ of the women liked the way family planning services providers attend to meet at the clinic while $40 \%$ of the women claimed not to it. Only $20 \%$ of the women believed modern family planning services providers are unfriendly, majority $80 \%$ of them disagree with the claim. Just $22.5 \%$ of the women claimed that service providers make modern family planning services expensive by attaching fees, most $77.5 \%$ of them disagree with the claim (Table 3).

Table 3: Distribution of Respondents Based On their Attitude towards the Use of Contraceptives.

\begin{tabular}{|c|c|c|}
\hline Variables & Frequency & Percentage (\%) \\
\hline \multicolumn{3}{|c|}{$\begin{array}{l}\text { Like women who practice modern Family } \\
\text { planning }\end{array}$} \\
\hline Strong agree & 40 & 20.0 \\
\hline Agree & 99 & 49.5 \\
\hline Disagree & 30 & 15.0 \\
\hline Strongly disagree & 31 & 15.5 \\
\hline \multicolumn{3}{|c|}{ Interested in discussing with women who practice modern Family Planning } \\
\hline Strong agree & 45 & 22.5 \\
\hline Agree & 100 & 50.0 \\
\hline Disagree & 25 & 12.5 \\
\hline Strongly disagree & 30 & 15.0 \\
\hline \multicolumn{3}{|c|}{ Scared of women who use modern family planning } \\
\hline Strongly agree & 25 & 12.5 \\
\hline Agree & 30 & 15.0 \\
\hline Disagree & 100 & 50.0 \\
\hline Strongly disagree & 45 & 22.5 \\
\hline \multicolumn{3}{|c|}{ Women using modern family planning methods are promiscuous } \\
\hline
\end{tabular}




\begin{tabular}{|c|c|c|}
\hline Strongly agree & 10 & 5.0 \\
\hline Agree & 19 & 9.5 \\
\hline Disagree & 50 & 25.0 \\
\hline Strongly disagree & 121 & 60.5 \\
\hline \multicolumn{3}{|c|}{ Like the way Family Planning services providers attend to meet at the clinic } \\
\hline Strongly agree & 50 & 25.0 \\
\hline Agree & 70 & 35.0 \\
\hline Disagree & 40 & 20.0 \\
\hline Strongly disagree & 40 & 20.0 \\
\hline \multicolumn{3}{|c|}{ Service providers are unfriendly } \\
\hline Strongly agree & 10 & 5.0 \\
\hline Agree & 30 & 15.0 \\
\hline Disagree & 70 & 35.0 \\
\hline Strongly disagree & 90 & 45.0 \\
\hline \multicolumn{3}{|c|}{ Service providers make modern family planning services expensive by attaching fees } \\
\hline Strongly agree & 20 & 10.0 \\
\hline Agree & 25 & 12.5 \\
\hline Disagree & 89 & 44.5 \\
\hline Strongly disagree & 66 & 33.0 \\
\hline
\end{tabular}

Table 4: Acceptance of Modern Contraceptive Methods among Respondents.

\begin{tabular}{|c|c|c|}
\hline Variables & Frequency & Percentage $(\%)$ \\
\hline \multicolumn{3}{|c|}{ Modern method ever used } \\
\hline Pills & 46 & 23.0 \\
\hline Injections & 57 & 28.5 \\
\hline Jelly/spermicides & 3 & 1.5 \\
\hline Condom & 50 & 25.0 \\
\hline Female sterilization & 3 & 1.5 \\
\hline Male sterilization & 1 & 0.5 \\
\hline Implant & 20 & 10.0 \\
\hline IUCD & 20 & 10.0 \\
\hline \multicolumn{3}{|c|}{ Currently using any of the method above } \\
\hline Yes & 147 & 73.5 \\
\hline No & 53 & 26.5 \\
\hline \multicolumn{3}{|c|}{ Modern method currently using } \\
\hline Pill & 42 & 21.0 \\
\hline IUCD & 23 & 11.5 \\
\hline Injections & 31 & 13.5 \\
\hline Jelly/spermicides & 12 & 6.0 \\
\hline Condom & 67 & 33.5 \\
\hline Female sterilization & 2 & 1.0 \\
\hline Male sterilization & 1 & 0.5 \\
\hline Implant & 22 & 11.0 \\
\hline \multicolumn{3}{|c|}{ Spousal communication about contraceptive method } \\
\hline Yes & 60 & 43.5 \\
\hline No & 78 & 56.5 \\
\hline
\end{tabular}

On the usage and acceptance of modern contraceptives, the distribution of the respondents showed that, $99 \%$ of the women had used one modern contraceptives or the other before, from the data $28.5 \%$ of them had used injections before, $25 \%$ condoms, $23 \%$ pills, $10 \%$ implant and IUCD, $1.5 \%$ jelly spermicides and female sterilization and $0.5 \%$ male sterilization. On their distribution based on the modern contraceptives currently being used, most $73.5 \%$ are currently using one method or other while the remaining $26.5 \%$ are not using any modern contraceptives at the moment. Out of the $73.5 \%$ using modern family planning methods currently, $15.5 \%$ are using injections, $21 \%$ pills, $33.5 \%$ condom, $11.5 \%$ IUCD, $11 \%$ implant, $6 \%$ jelly spermicides, $1 \%$ female sterilization and $0.5 \%$ male sterilization (Table 4 ).

\section{Discussion}

Studies from developing countries have shown that sociodemographic characteristics are some of the predictors of an individual's contraceptive choice Okezie et al. 2010. The mean age for the study population was 32.7 years. This means that half $(50 \%)$ of the study population will in the next 16 years still be in the reproductive age group (15-49 years), and would require one form of contraception or the other to control their fertility. These respondents have 2-3 children per individual and therefore will require a contraceptive method to delay, postpone or terminate child bearing. It is therefore necessary to ascertain the knowledge, the attitudes and the acceptance of this study population towards modern contraceptive uptake. The study population had good literacy level as $36.5 \%$ and $16 \%$ of the respondents have primary, secondary and tertiary education respectively.

The benefit of this is that they are more likely to posses the ability to understand health promotions in general and on contraception at the antenatal clinics, media, contraceptive awareness programmes, 
from posters and brochures. The predominantly Christian dominated South-West geopolitical zone in Nigeria reflected in the study group as $60.5 \%$ were Christians. And the remaining $29.5 \%$ were either Muslims or Tradionalist. These variations in religious affiliations and ideology in the study population could also shape their beliefs, attitude and practice of contraceptive usage [10]. Also this study also reflected the predominantly Yourubas in the SouthWest geopolitical zone in Nigeria as $42.5 \%$ of the study population were Yoruba's and there rest were Ibos, Hausas and Ijaw.

The knowledge and awareness in the study group was very high, as $78.5 \%$ of respondents have heard about contraceptives. The most common method heard about was pills as it take $22.3 \%$ out of $78.5 \%$. The awareness on modern contraceptive methods in Nigeria has grown over time. This is because this result is in contrast to the Nigerian Demographic and Health Survey(2003) where more than half (56\%) of Nigerian women aged between $15-49$ years had never heard a message on family planning methods [11,12].

The source of information for respondents was mostly hospital based-35\% out of the $78.5 \%$ of respondents which had heard about modern contraceptives heard of family planning from doctors and nurses. This high awareness is due to the high literacy rate among the study group and the health education and counselling from doctors and nurses during antenatal visits. Knowledge regarding the concept of family planning reflects the effectiveness of the educational sessions offered by health care providers in the area in general and in the study group in particular. One of the greatest obstacles to family planning in developing countries is knowledge. An individual can only accept to take contraceptives if she has an in depth knowledge of what contraception are the side effects and above all the benefits accruing to the individual for using it. The study populations of post-natal patients have good knowledge about contraception as they were able to identify at least one or two contraceptive methods (Condom 19.1\%, daily pill $22.3 \%$ and $17.8 \%$ condom). These results were similar to works done in Tanzania where $80 \%$ of respondents knew at least three modern contraceptive methods [13].

However, the in depth knowledge of modern contraceptive methods among respondents is still vital. Advocacy by care providers, Social workers, Non-Governmental Organizations (NGOs), various Governments in Nigeria need to be intensified to improve the knowledge and acceptance of modern contraceptive methods. The attitude of the study group was favourably disposed to contraceptive patronage. This is because $69.5 \%$ of them actually agree to like women who practiced modern family planning methods, $72.5 \%$ also claimed to be interested in discussing modern Family Planning and debunks the idea of being scared of women who use modern Family Planning. Also $85.5 \%$ of the study population disagrees with the fact that women who use modern Family Planning are promiscuous, while $60 \%, 80 \%$ and $77.5 \%$ of the study population like Family Planning meetings at the clinic disagrees that Family Planning service providers are unfriendly and that they make family planning services expensive by attaching fees respectively.
The acceptance of modern family planning methods in this study population was very high, as virtually all of them had used at least one modern contraceptives in the past with the most being injections-28.5\% and condoms-25\%. This was further proved as $73.5 \%$ of the study population is currently using one contraceptive or the other as against $26.5 \%$ who are not. The most currently used family planning method was the injection (33.5\%) followed by the pills (21\%) and the condoms (15.5\%). There is a low level of Spousal communications among the respondents as only $43.5 \%$ of respondents discuss contraception with spouses and partners.

\section{Conclusion}

There is high level of awareness of contraception among women attending post natal clinic in Ayeka Basic Health Center of Okitipupa Local Government Area. Male condom was the most commonly used method. There is a low level of Spousal communications among the respondents contraception with spouses and partners.

\section{Recommendations}

The following are the recommendations to enhance contraceptive use based on findings of this study:

i. Education of the community on importance of having smaller families and empowerment of women should be intensified.

ii. Encouraging gender balance by changing community attitude towards position/status of women in a household and in a society as a whole should be strengthened. This would improve their participation in household decisions including those related to fertility and contraceptive use.

iii. Increase in community campaigns to raise awareness on importance of modern contraceptives among males (husbands) should be emphasized and should go along with those involving women.

\section{Limitations of the Study}

The study was delimited to knowledge, attitude and acceptance of modern family planning methods among women attending post-natal clinic in Ayeka Basic health centre in Okitipupa Local Government Area, Ondo State, Nigeria. The study was not extended to women attending post natal clinic outside government owed health centre to ensure conformity of standards.

\section{Directions for Further Research}

Future researchers should carry out similar research among women attending post natal clinics in private hospitals and those attending traditional birth attendant homes. Comparative analysis could be carried out to measure their variance.

\section{Sources of Funding of the Study}

The study was financed solely by the researchers.

\section{References}

1. Population Reports (1999) Ending Violence Against Women. Issues in World Health 27(4):1-44. 
2. Umoh AV, Abah GM, Ekanem US (2012) A study of fertility intentions of women in Uyo. Journal of Public Health and Epidemiology 4(1): 14-18.

3. Ekong EE (2003) An introduction to Rural Sociology. $2^{\text {nd }}$ edn, Dore publications, Uyo, Nigeria pp. 143-151.

4. Weldegerima B, Denekew A (2008) Women's knowledge, preferences, and practices of modern contraceptive methods in Woreta, Ethiopia. Research in Social and Administrative Pharmacy 4(3): 302-307.

5. National Population Commission (NPC) [Nigeria] and ICF Macro (2009) Nigeria Demographic and Health Survey 2008. Abuja, Nigeria: National Population Commission and ICF Macro, Calverton, Maryland, USA.

6. Nwachukwu I, Obasi 00 (2008) Use of Modern Birth Control Methods among Rural Communities in Imo State, Nigeria. African Journal of Reproductive Health 12(1): 101-108.

7. Gaur DR, Goel Munish Kumar, Goel Meenu (2008) Contraceptive practices and related factors among female in predominantly rural Muslim area of North India. The Internet Journal of World Health and Societal Politics 5(1).
8. Oyedokun AO (2007) Determinants of contraceptive Usage: Lessons from Women in Osun State, Nigeria. J Humanities Social Sciences 1: 1-14.

9. Abiodun OM, Balogun OR (2009) Sexual activity and contraceptive use among young female students of tertiary educational institution in Ilorin, Nigeria. Contraception 79(2): 146-149.

10. Igbudu U, Okoedions S, Peremene E, Eghafona K (2011) Religious beliefs and family practices of married women in zone 5 , police barracks in Nigeria, Ozea journal of social sciences.

11. National Population Commission (2004) Nigeria Demographic and Health Surveys 2003, Federal Republic of Nigeria and ORC Macro, Calverton, Maryland, USA, pp. 104.

12. NDHS (2012) Nigeria Demographic and Health Survey 2003. Journal of public Health and Epidemiology 4(1): 14-18.

13. Kalu AC, Umeora OU, Adeoye SI (2012) Experiences with provision of post-abortion care in a university teaching hospital in a South-East Nigeria: a five year review. Afr J Reprod Health 16(1): 105-112.

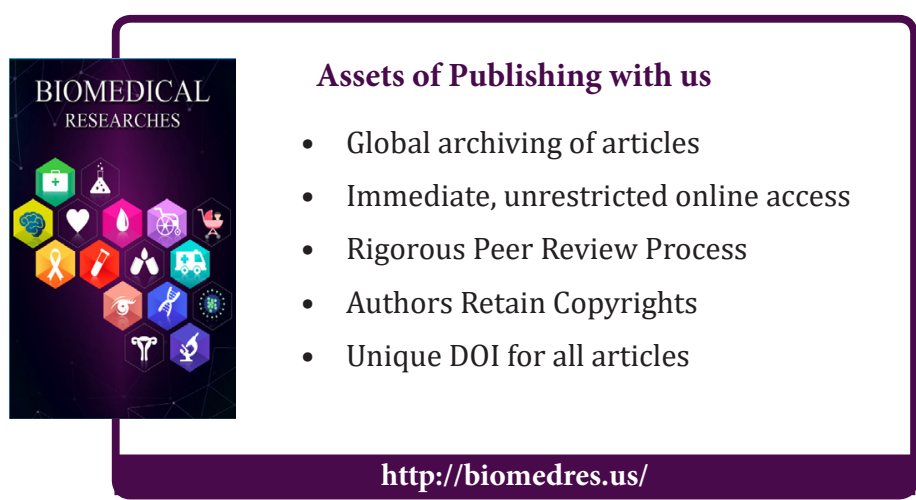

